\title{
Article
}

\section{Westerly Winds in the Southern Ocean During the Last Glacial Maximum Simulated in CCM3}

\author{
Seong-Joong Kim* and Bang Yong Lee \\ Korea Polar Research Institute, KORDI \\ Songdo Techno Park, Incheon 406-840, Korea
}

\begin{abstract}
We investigated the response of the westerly winds over the Southern Ocean (SO) to glacial boundary conditions for the Last Glacial Maximum using the CCM3 atmospheric general circulation model. In response to glacial boundary conditions, the zonally averaged maximum SO westerly winds weakened $20-35 \%$ and were displaced toward the equator by 3-4 degrees. This weakening of the SO westerly winds arose from a substantial increase in mean sea level pressure (MSLP) in the southern part of the SO around Antarctica relative to the northern part. The increase in MSLP around Antarctica is associated with a marked temperature reduction caused by an increase in sea ice cover and ice albedo feedback during the glacial time. The weakened westerly winds in the SO and their equator-ward displacement might play a role in reducing the atmospheric $\mathrm{CO}_{2}$ concentration by reducing upwelling of the carbon rich deep water during the glacial time.
\end{abstract}

Key words : atmospheric $\mathrm{CO}_{2}$, glacial period, southern ocean, westerly wind, numerical model

\section{Introduction}

The glacial-interglacial fluctuation of atmospheric $\mathrm{CO}_{2}$ concentration plays an important role in amplifying the climate change initiated by orbital parameters' variability. Analyses of air bubbles trapped in Antarctic ice cores have shown that for about the past 0.7 million years, the atmospheric $\mathrm{CO}_{2}$ concentration fluctuates from about 180 ppmv in glacial to 300 ppmv in interglacial periods (Sigenthaler et al. 2005). In order to explain the glacial $\mathrm{CO}_{2}$ reduction, many hypotheses have been suggested; and hypotheses based on the Southern Ocean (SO) have been shown to be more valid than others (Broecker and Henderson 1998; Sigman and Boyle 2000; Anderson et al. 2009).

Hypotheses based on the SO rely on the strong interaction between surface and deep ocean. In the SO, the surface winds are strongest near $50^{\circ} \mathrm{S}$ north of Drake Passage and decreases towards the south. This leads to the divergence of surface water and draws deep water $(\sim 15$

\footnotetext{
*Corresponding author. E-mail : seongjkim@kopri.re.kr
}

Sv) into the surface at the latitude band of Drake Passage due to topographic constraint (Toggweiler and Samuels, 1995). Because the deep water provides abundant nutrients and dissolved inorganic carbon to the ocean's surface, a change in the rate of upwelling of deep water can influence the atmospheric $\mathrm{CO}_{2}$ budget. Atmospheric $\mathrm{CO}_{2}$ drawdown could be possible by either increasing the productivity or inhibiting the out-gassing of inorganic carbon to the atmosphere. Increasing biological productivity could readily reduce the atmospheric $\mathrm{CO}_{2}$ concentration to glacial levels (Knox and McElroy 1984; Sarmiento and Toggweiler 1984; Siegenthaler and Wenk 1984). However, this hypothesis suffers from a lack of evidence (Boyle 1992; Sigman and Boyle 2000; Anderson et al. 2002). People therefore have searched for alternative ways to suppress $\mathrm{CO}_{2}$ out-gassing to the atmosphere.

Three hypotheses to illustrate the mechanism, which could limit the $\mathrm{CO}_{2}$ out-gassing, have been suggested, even though they have some points to be clarified. First, by analysing nitrogen-isotope records obtained in the $\mathrm{SO}$ together with geochemical tracers of biogenic matter, several studies suggested that the ocean stratification 
increased south of the Polar Front during the glacial time and this reduced the $\mathrm{CO}_{2}$ leak from ocean to atmosphere (Francois et al. 1997; Toggweiler 1999; Sigman and Boyle 2000; Gildor et al. 2002). However, Keeling and Visbeck (2001) argued that the more stratified SO during glacial time would weaken southward eddy transports due to the flattening of the slope of the isopycnal surfaces. The weakened southward eddy transports would allow more deep water to upwell rather than inhibiting as suggested by authors mentioned above.

Second, Stephens and Keeling (2000) argued that increased perennial sea ice cover and melt water around the SO during the glacial time inhibited the sea-air outgassing and reduced the atmospheric $\mathrm{CO}_{2}$ concentration. By increasing the Antarctic sea ice cover using a box model, they were able to reduce the atmospheric $\mathrm{CO}_{2}$ concentration by about $65 \mathrm{ppm}$. This hypothesis requires a continuous and complete coverage of sea ice in the Antarctic zone through the season (Sigman and Boyle, 2001). However, recent sea ice reconstructions (Crosta et al. 1998; Gersonde et al. 2005) suggested that sea ice had a more intensified seasonal cycle during the glacial times than the reconstruction by CLIMAP $(1976,1981)$, which showed almost complete coverage of sea ice in all seasons.

Third, the northward shift of westerly winds was suggested to inhibit the $\mathrm{CO}_{2}$ out-gassing through a weakening of the Ekman divergence in the SO (Sigman and Boyle 2000; Toggweiler et al. 2006; Toggweiler 2009; Anderson et al. 2009). McCulloch et al. (2000) obtained the northward displacement of westerlies during the glacial time by analysing lacustrine palynologic records along the western Andean front of Chile. Based on pollen types which contain the information of the vegetation migration near the tip of South America, Moreno et al. (1999) suggested that the SO westerly winds were shifted northward by $7-10^{\circ}$ in the LGM. Heusser (1989) also obtained a northward shift of the SO westerlies. Although preponderance of the evidence showed the northward displacement of the mean position of the glacial westerlies, a southward shift was also suggested. For example, Markgraf (1987, 1989) suggested a poleward shift of the mean position of westerly winds.

In addition to a meridional shift of the westerlies, a change in their strength would obviously influence deepwater upwelling around Antarctica, but the strength of the westerly winds over the SO during the glacial time remains highly uncertain. Some proxy records such as dust concentrations, including sea-salt chlorides, recorded in Antarctic ice cores $\left(74^{\circ} \mathrm{S}, 124^{\circ} \mathrm{E} ; 78^{\circ} \mathrm{S}, 106^{\circ} \mathrm{E}\right)$, suggest an enhanced atmospheric circulation with a drier climate than at present in the southern high latitudes (Petit et al. 1981; De Angelis et al. 1987). Some authors attribute the SO westerly winds' intensification to an increase in the Equator-to-Pole temperature gradient (Keeling and Visbeck 2001). However, this might be an overly simplified view because low-level winds depend on regional temperature gradient rather than global-scale temperature change (Sigman and Boyle 2001). Moreover, there is a large uncertainty in linking eolian sediments or dust concentration directly to the change in surface winds and the proxy records are generally highly localized and not representative of the large-scale surface wind pattern. This study aims to investigate the SO westerly winds' response to glacial boundary conditions using a numerical model and to analyze the westerly response's cause.

The northward shift of the westerlies during glacial time in the SO and associated weakening of Ekman divergence seemed to play a role in reducing the atmospheric $\mathrm{CO}_{2}$ concentration. However, the change in the strength of westerly winds and its possible role in glacial $\mathrm{CO}_{2}$ fluctuation has not been rigorously studied. The purpose of this study is to investigate the response of westerly winds over the SO to the glacial boundary conditions and to analyse the cause of the change using a numerical model.

\section{Model description and experimental design}

In order to investigate the response of the polar westerlies over the Southern Ocean, we used the National Center for Atmospheric Research (NCAR) Community Climate Model version 3 (CCM3) atmospheric general circulation model with 3.6 .6 physics. This study uses horizontal resolution of T42 $\left(2.8125^{\circ}\right.$ in Gaussian grid). The model has 18 vertical levels in a hybrid coordinate that is terrain-following at the surface and reduces to a pressure coordinate in the upper atmosphere. This model represents important physical processes as Kiehl et al. (1998a, 1998b) described in detail. The CCM3 includes a comprehensive model of land surface processes known as the NCAR Land Surface Model (LSM; Bonan 1998).

We performed two experiments. The first reproduces the modern climate and is hereinafter referred to as MODern (MOD). The modern climate simulation was forced by prescribed climatologically averaged monthly sea-surface temperatures (SSTs) and sea ice distributions provided by NCAR. We used a $\mathrm{CO}_{2}$ concentration of 355 
ppm and a contemporary land mask and topography. The second experiment includes glacial boundary conditions for the Last Glacial Maximum (LGM), i.e., reduced atmospheric $\mathrm{CO}_{2}$ concentration to $200 \mathrm{ppm}$ following ice core data (e.g. Siegenthaler et al. 2005), glacial surface topography following Peltier's (1994) ICE-4G reconstruction ( $4^{\text {th }}$ generation ice sheet reconstruction), a modified land mask to account for the lower sea level (about $120 \mathrm{~m}$ from Clark et al. 2001) than present, orbital parameters for 21,000 years before present according to Berger (1978), and monthly climatological SST for the LGM based on the climate long-range investigation mapping and prediction (CLIMAP, 1981) reconstruction. We used contemporary vegetation and soil types except for the glaciated surfaces and land points arising from sea-level reduction (these were assigned median vegetation and soil types for the CCM3).

\section{Results}

With modern and glacial boundary conditions, we integrated the model for 10 years and analyzed the last five years. Because in the southern hemisphere the seasonal fluctuations are not as large as in the northern hemisphere, we analyzed the annual-mean result averaged for the last five years. Before we investigated the SO westerly winds' response, we examined the numerical model's performance at reproducing present climate.

Fig. 1 displays the geographic distribution of the annual mean simulated and observed surface winds at $1000 \mathrm{hPa}$ (hecto pascal) and mean sea level pressure (MSLP). The observed data are an NCEP (National Center of Environmental Protection) /NCAR reanalysis. In the SO, the strong westerly winds typically are observed and the weak easterly winds are observed around Antarctica. The a) Surface Wind (OBS)

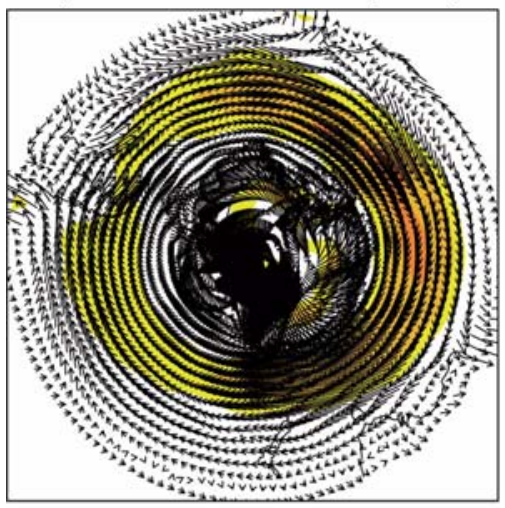

10

b) MSLP (OBS)

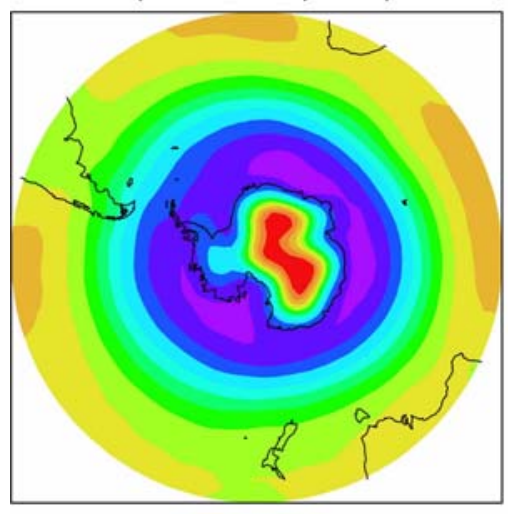

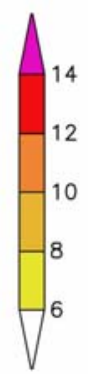

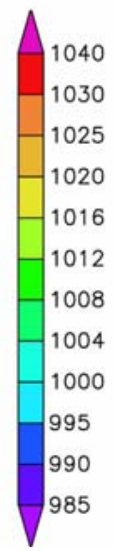

c) Surface Wind (MOD)

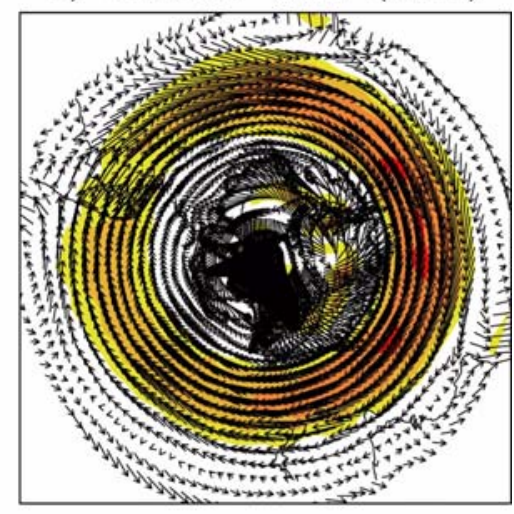

10

d) MSLP (MOD)

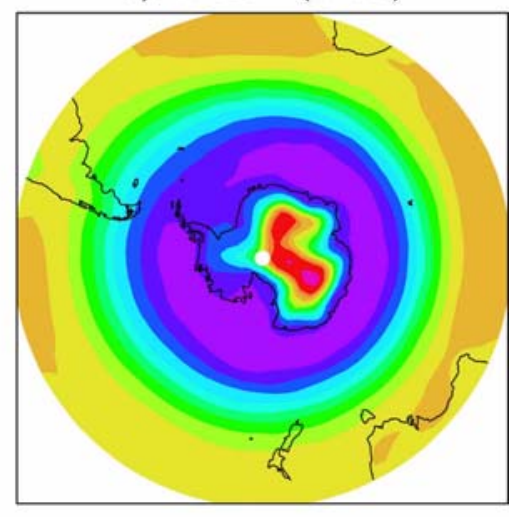

Fig. 1. Geographic distribution of the annual-mean observed and simulated surface wind vectors with wind magnitude and mean sea level pressure (MSLP). The observed data are from NCEP/NCAR reanalysis. 
westerly winds are stronger in the eastern part of the SO than in the western part, in association with the distribution of the MSLP, which decreases gradually from subtropical to subpolar regions and increases toward Antarctica. The minimum MSLP between $60-70^{\circ} \mathrm{S}$ is the Antarctic circumpolar trough, which is an almost

\section{a) LGM-MOD Surface Wind}
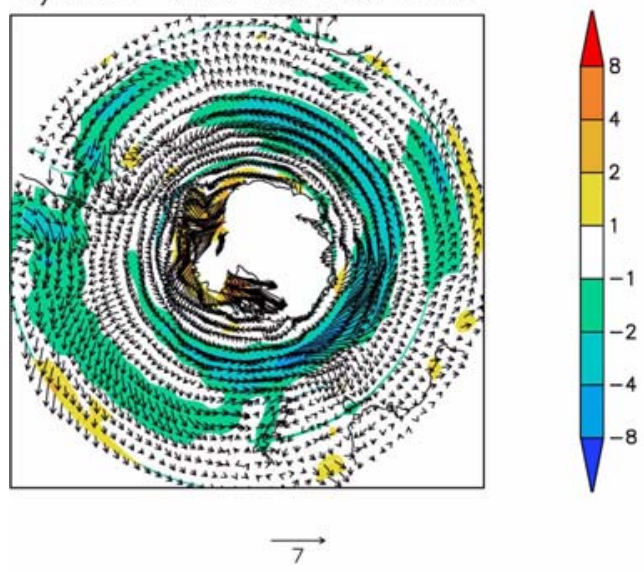

b) LGM-MOD MSLP

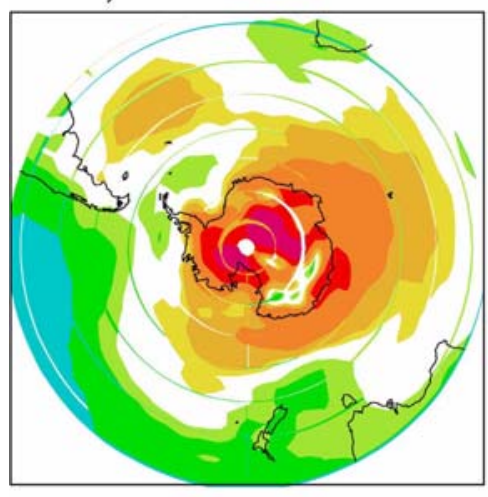

c) LGM-MOD SAT
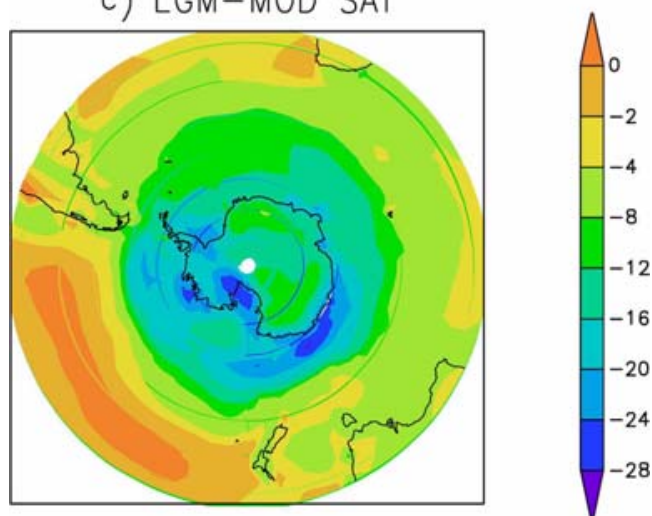

Fig. 2. Geographic distribution of the change in annual mean a) surface winds, b) MSLP, and c) surface air temperature (SAT) between MOD and LGM. continuous zonal belt around Antarctica with very low surface pressure values of less than $985 \mathrm{hPa}$. Generally a high MSLP prevails over the continent, although the MSLP in the interior should be regarded as merely a qualitative indicator because of uncertainties caused by high orography. Even though simulation tends to overestimate the wind's magnitude and associated Antarctic trough compared to those of the observation, the model reproduces the SO westerly winds and MSLP reasonably well.

Fig. 2 displays the geographic distribution of the change in annual mean surface winds, MSLP, and surface air temperature (SAT). In the wind fields, the shading represents a change in the wind's magnitude. With glacial boundary conditions, the $\mathrm{SO}$ westerlies are simulated to be about 20-35\% weaker overall than the MOD. The reduction is especially large in the Indian sector of the SO, where the wind's speed is reduced by more than $4 \mathrm{~m} \mathrm{~s}^{-1}$, which is about a $40 \%$ reduction. Wide-spread reduction of surface winds by more than $1 \mathrm{~m} \mathrm{~s}^{-1}$ is also present in the northern part of the Atlantic and Pacific sectors of the SO. The easterly winds around Antarctica, on the other hand, simulated to be slightly stronger in the LGM than in the MOD.

In order to illustrate what caused the SO westerly to weaken under glacial conditions, we present the change in MSLP between the two experiments (Fig. 2b). In the LGM, the MSLP increases gradually toward Antarctica from the mid-latitudes, and its increase is especially large in the Indian sector of the SO. The biggest increase is found in the Antarctic interior but, as noted above, it might not be meaningful in eastern Antarctica because of the high orography. In subtropical regions of the midlatitudes, on the other hand, the MSLP decreases, especially in the Pacific sector. The increase in the MSLP around Antarctica and the decrease in subtropical regions reduces meridional pressure gradient, consequently weakening the westerly winds.

Because the change in MSLP is closely linked to the change in surface air temperature (SAT), we examine the change in SAT in the LGM (Fig. 2c). The change in SAT appears to be consistent with the change in the MSLP, as we expected. With glacial boundary conditions, the SAT decreases everywhere and the reduction becomes large toward Antarctica. The biggest SAT reduction is off Wilkes Land and the eastern Ross Sea, where the MSLP increases substantially (Fig. 2b). The SAT reduction is lowest where there is a reduction of the MSLP in the Pacific sector's subtropical regions. 
a) NCAR SST \& Sea Ice (Ann)
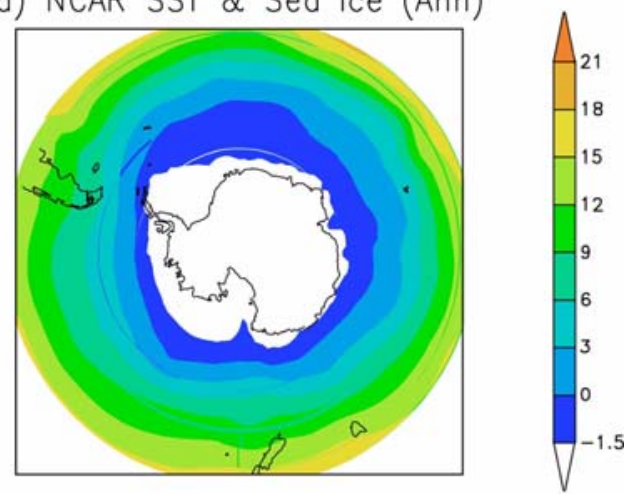

b) CLIMAP SST \& Sea Ice (Ann)
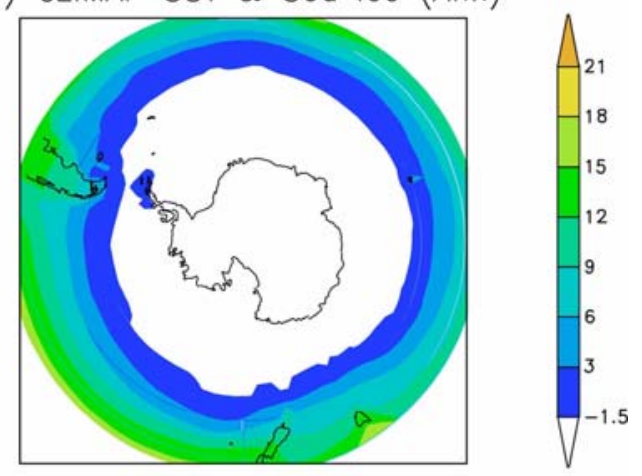

c) CLIMAP-NCAR SST (Ann)

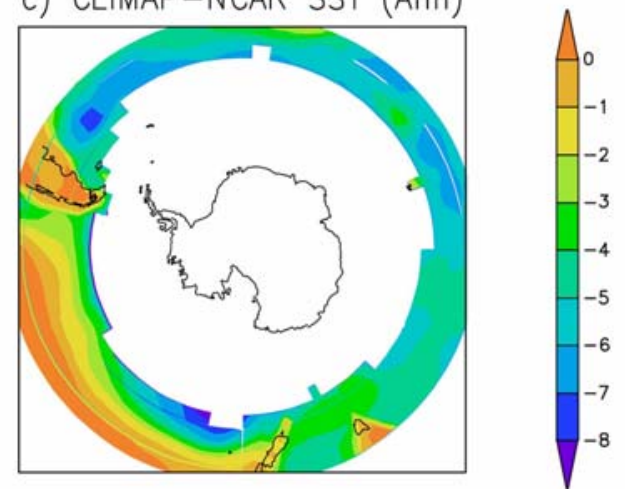

Fig. 3. Geographic distribution of the annual mean sea surface temperature (SST) and sea ice for a) modern from NCAR and b) LGM from CLIMAP (1981) reconstructions, and c) the change between the periods.

The marked SAT reduction around Antarctica in the LGM is associated with the extension of sea ice. Fig. 3 shows the geographic distribution of the annual mean SST and sea ice used to force the MOD and LGM simulations. The sea ice for the LGM simulation is from the CLIMAP (1981) reconstruction based on ice rafted debris. A marked increase in sea ice appears in the LGM. Where a) Surface Wind

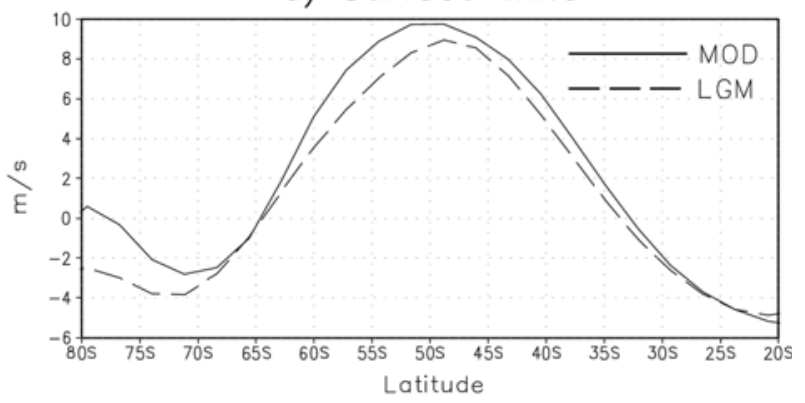

b) MSLP

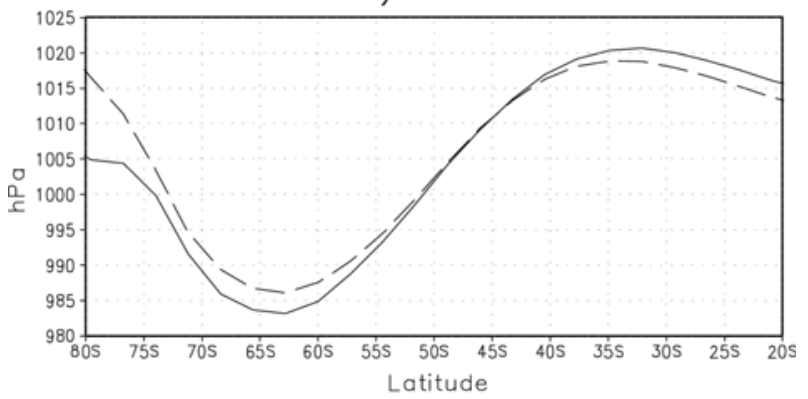

c) LGM-MOD SAT

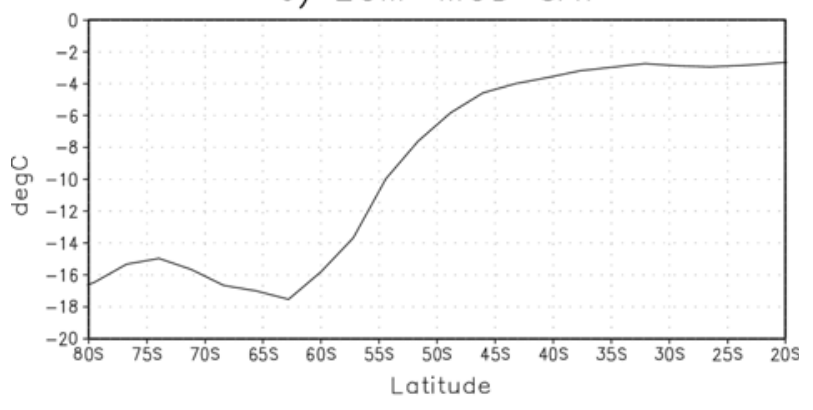

Fig. 4. Zonally averaged annual mean a) zonal surface wind, b) MSLP, c) change in SAT. Units are in $\mathrm{m} \mathrm{s}^{-1}$, hPa, and ${ }^{\circ} \mathrm{C}$, respectively.

the ocean became sea ice, the SAT is dramatically reduced because of the marked difference in surface reflectivity between water and sea ice. Open water has low, less than $10 \%$, reflectivity of short wave radiation, compared to sea ice, which has a reflectivity of more than $70 \%$.

To investigate whether the SO westerly winds' axis is meridionally displaced, we examine zonally averaged quantities. Fig. 4 displays the zonally averaged annual mean zonal surface winds and MSLP for the MOD and LGM experiments, and the change in SAT between the two experiments. In the MOD experiment, the surface winds peak in the southern latitudes around $52^{\circ} \mathrm{S}$, with a wind speed of about $10 \mathrm{~m} \mathrm{~s}^{-1}$. In the LGM, the maximum westerly's mean position is displaced toward the equator by roughly $3-4^{\circ}$. This is consistent with proxy estimates 
(Sigman and Boyle 2000, 2001). As the geographic distribution of the change in surface winds shows, the zonal-mean zonal winds decrease overall by about 20$30 \%$ in latitudes of the $\mathrm{SO}$, and at the maximum decrease by about $20 \%$.

The zonally averaged MSLP is in large part associated with the weakening of westerlies in the LGM, that is caused by a reduction in meridional pressure gradient. In the LGM, the zonal-mean MSLP increases substantially, by several $\mathrm{hPa}$, in high southern latitudes of the Antarctic trough between $60-70^{\circ} \mathrm{S}$, whereas at latitudes of the subtropical high pressure around $35^{\circ} \mathrm{S}$, MSLP decreases. This change in MSLP eventually reduces merdional pressure gradient. As noted above, the change in zonalmean MSLP in the LGM is consistent with the change in zonal-mean SAT, which decreases remarkably toward the high southern latitudes, and at $50^{\circ} \mathrm{S}$ it decreases by up to about $18^{\circ} \mathrm{C}$. The large SAT reduction in subpolar latitudes is caused partly by the large amount of sea ice, which was specified based on reconstruction (CLIMAP 1981). This result indicates that the increase in the amount of sea ice in the $\mathrm{SO}$ is partly responsible for the $\mathrm{SO}$ westerly winds' weakening during glacial times.

\section{Discussion and conclusion}

Coupled model simulations also obtained the weak SO westerly winds in response to glacial conditions. For example, using an atmosphere-ocean coupled model developed at the Canadian Center for Climate Modeling and Analysis, Kim et al. (2003) obtained a substantially reduced, by more than $4 \mathrm{~m} \mathrm{~s}^{-1}$, intensity of SO westerly winds in their LGM simulation almost everywhere around Antarctica. By analyzing four coupled model results of the LGM simulation from the second phase of the Paleoclimate Modelling Intercomparison Project (PMIP2), Rojas et al. (2008) obtained the decreased SO westerly intensities near the surface and the decreased upwelling in the SO in three out of four models. They argued that although the LGM atmosphere is colder than present and the equator-to-pole gradient increases, the tropospheric temperature gradient decreases, weakening the SO westerlies.

The SO westerly winds' shift toward the equator under glacial conditions mirrors their pole-ward shift under global warming. Observations suggest that the SO westerlies have been shifting pole-ward over the past 40 years (Hurrell and van Loon 1994) and many models project the westerlies to continuously intensify and shift pole-ward in the future (Kushner et al. 2001; Yin 2005; Fyfe and Saenko 2006). The pole-ward intensifying westerly winds are consistent with the southern annular mode's shifting toward a high-index state (Thompson et al. 2000). As the introduction mentions, paleoclimatic proxy evidence for the SO westerlies' intensity and shifting in the LGM is vague. In a recent analysis of pollen proxy records, Moreno et al. (1999) argue that the SO westerly storm track shifted toward the equator by $7^{\circ}$ in the LGM, but uncertainties are high. A further study of the paleoclimate proxy evidence to evlauate the intensity of the SO westerly winds are desirable.

The results of this study and other LGM simulations, and the SO westerlies' responses under the global warming scenario, suggest that the SO westerly winds are weak and shifted to the equator under glacial conditions. In conclusion, the growing sea ice in the SO weakened the westerly winds and shifted them equatorward, which presumably played an important role in reducing the atmospheric $\mathrm{CO}_{2}$ concentration by inhibiting the outgassing of inorganic carbon in the SO during glacial periods.

\section{Acknowledgements}

The authors would like to acknowledge the technical support from KISTI (Korea Institute of Science and Technology Information). This study was supported by the Korea Polar Research Institute's projects on the Integrated Research on the Composition of Polar Atmosphere and Climate Change (COMPAC) (PE09030) and the Paleoclimate Modeling Study for Polar Regions (PE09120).

\section{References}

Anderson RF, Ali S, Bradtmiller LI, Nielsen SH, Fleisher MQ, Anderson BE, Burkle LH (2009) Wind-driven upwelling in the Southern Ocean and the deglacial rise in Atmospheric $\mathrm{CO}_{2}$. Science 323:1443-1448

Anderson RF, Chase Z, Fleisher MQ, Sachs J (2002) The Southern Ocean's biological pump during the Last Glacial Maximum. Deep-Sea Res II 49:1909-1938

Berger A (1978) Long-term variations of daily insolation and Quaternary climate changes. J Atmos Sci 35:23622367

Bonan G (1998) The land surface climatology of the NCAR land surface model coupled to the NCAR community climate model. J Climate 11:1307-1326

Boyle EA (1992) Cadmium and ${ }^{13} \mathrm{C}$ paleochemical ocean distributions during the stage 2 glacial maximum. Annu 
Rev Earth Planet Sci 20:245-287

Broecker WS, Henderson GM (1998) The sequence of events surrounding Termination II and their implications for the cause of glacial-interglacial $\mathrm{CO}_{2}$ changes. Paleoceanography 13:352-364

Clark PU, Mix AC, Bard E (2001) Ice sheets and sea level of the Last Glacial Maximum. EOS Transactions AGU 82(22):241-247

CLIMAP (1976) The surface of the ice-age earth. Science 191:1131-1136

CLIMAP (1981) Seasonal reconstructions of the earth's surface at the last glacial maximum. Geological Society of America, Map Chart Series 36

Crosta X, Pichon J-J, Burckle LH (1998) Reappraisal of Antarctic seasonal sea-ice at the Last Glacial Maximum. Geophys Res Lett 25:2703-2706

De Angelis M, Barkov NI, Petrov VN (1987) Aerosol concentrations over the last climatic cycle (160 kyr) from an Antarctic ice core. Nature 325:318-321

Francois R, Altabet MA, Yu E-F, Sigman DM, Bacon MP, Frank M, Bohrmann G, Bareille G, Labeyrie LD (1997) Contribution of southern ocean surface-water stratification to low atmospheric $\mathrm{CO}_{2}$ concentrations during the last glacial period. Nature 389:929-935

Fyfe JC, Saenko OA (2006) Simulated changes in the extratropical Southern Hemisphere winds and currents. Geophys Res Lett 33. doi:10.1029/2005GL025332

Gersonde R, Crosta X, Abelmann A, Armand L (2005) Seasurface temperature and sea ice distribution of the southern ocean at the EPILOG Last Glacial Maximum a circum-Antarctic view based on siliceous microfossil records. Quat Sci Rev 24:869-896

Gildor H, Tziperman E, Toggweiler JR (2002) Sea ice switch mechanism and glacial-interglacial $\mathrm{CO}_{2}$ variations. Glob Biogeochem Cycle 16. doi:10.1029/2001GB001446

Heusser CJ (1989) Southern westerlies during the last glacial maximum. Quat Res 31:423-425

Hurrell JW, van Loon H (1994) A modulation of the atmospheric annual cycle in the Southern Hemisphere. Tellus 46A:325-338

Keeling RF, Visbeck M (2001) Antarctic stratification and glacial $\mathrm{CO}_{2}$. Nature 412:605-606

Kiehl JT, Hack JJ, Bonan BG, Boville BA, Williamson DL, Rasch P (1998a) The national center for atmospheric research community climate model: CCM3. J Climate 11:1131-1149

Kiehl JT, Hack JJ, Hurrell J (1998b) The energy budget of the NCAR community climate model: CCM3. J Climate 11: $1151-1178$

Kim S-J, Flato GM, Boer GJ (2003) A coupled climate model simulation of the last glacial maximum, Part 2: approach to equilibrium. Climate Dyn 20:635-661

Knox F, McElroy MB (1984) Changes in atmospheric $\mathrm{CO}_{2}$ : influence of the marine biota at high latitude. J Geophys Res 89:4629-4637

Kushner P, Held I, Delworth T (2001) Southern Hemi- sphere atmospheric circulation response to global warming. J Climate 14:2238-2249

Markgraf V (1987) Paleoenvironmental changes at the northern limit of the subantarctic Nothofagus forest, Lat $37^{\circ} \mathrm{S}$, Argentina. Quat Res 28:119-129

Markgraf V (1989) Southern westerlies during the last glacial maximum-reply. Quat Res 31:426-432

McCulloch RD, Bently MJ, Purves RS, Hulton NRJ, Sugden DE, Clapperton CM (2000) Climate inferences from glacial and palaeoecological evidence at the last glacial termination, southern South America. J Quat Science 15:409-417

Moreno PI, Lowell TV, Jacobson Jr GL, Denton GH (1999) Abrupt vegetation and climate changes during the last glacial maximum and last termination in the Chilean Lake District: a case study from Canal de la Puntilla $\left(41^{\circ} \mathrm{S}\right)$. Geogr Ann Ser 81:285-311

Peltier WR (1994) Ice age paleotopography. Science 265: 195-201

Petit JR, Briat M, Royer A (1981) Ice age aerosol content from East Antarctic ice core samples and past wind strength. Nature 293:391-394

Rojas M, Moreno P, Kageyama M, Crucifix M, Hewitt C, Abe-Ouchi A, Ohgaito R, Brady EC, Hope P (2008) The Southern Westerlies during the last glacial maximum in PMIP2 simulations. Climate Dyn 32(4). doi:10.1007/s00382-008-0421-7

Sarmiento JL, Toggweiler R (1984) A new model for the role of the oceans in determining atmospheric $\mathrm{pCO}_{2}$. Nature 308:621-624

Siegenthaler U, Stocker T, Monnin E, Luthi D, Schwander J, Stauffer B, Raynaud D, Barnola J-M, Fischer H, Masson-Delmotte V, Jouzel J (2005) Stable carbon cycle-climate relationship during the late pleistocene. Science 310:1313-1317

Siegenthaler U, Wenk T (1984) Rapid atmospheric $\mathrm{CO}_{2}$ variations and ocean circulation. Nature 308:624-626

Sigenthaler U, Monnin E, Kawamura K, Spahni R, Schwander J, Stauffer B, Stocker TF, Barnola J-M, Fischer H (2005) Supporting evidence from the EPICA Dronning Maud Land ice core for atmospheric $\mathrm{CO}_{2}$ changes during the past millennium. Tellus 57B:51-57

Sigman DM, Boyle EA (2000) Glacial/interglacial variations in atmospheric carbon dioxide. Nature 407:859-869

Sigman DM, Boyle EA (2001) Antarctic stratification and glacial $\mathrm{CO}_{2}$-reply. Nature 412:606

Stephens BB, Keeling RF (2000) The influence of Antarctic sea ice on glacial-interglacial $\mathrm{CO}_{2}$ variations. Nature 409:171-174

Thompson DWJ, Wallace JM, Hegerl GC (2000) Annular modes in the extratropical circulation. Part II: Trends. J Climate 13:1018-1036

Toggweiler JR, Samuels B (1995) Effect of Drake Passage on the global thermohaline circulation. Deep-Sea Res 42: 477-500

Toggweiler JR (1999) Variations of atmospheric $\mathrm{CO}_{2}$ by 
ventilation of the earth's deepest water. Paleoceanography 14:571-588

Toggweiler JR (2009) Shifting westerlies. Science 323: 1434-1435. doi:10.1126/science.1169823

Toggweiler JR, Russell JL, Carson SR (2006) Midlatitude westerlies, atmospheric $\mathrm{CO}_{2}$, and climate change during the ice ages. Paleoceanography 21. doi:10.1029/2005PA001154
Yin JH (2005) A consistent poleward shift of the storm tracks in the simulations of 21 st century climate. Geophys Res Lett 32. doi:10.1029/2005GL023684

Received Sep. 16, 2009

Revised Nov. 13, 2009

Accepted Dec. 1, 2009 